\title{
A Study Of Ethical Work Climates Between Filipino And Taiwanese Accountants
}

\author{
Catherine M. Gallano, Uni-President (Philippines) Corporation, Philippines
}

\begin{abstract}
The purpose of this study is to find if there is a significant difference between the Filipino and Taiwanese accountants on the perceived work climate value. The 36-item revised version of Ethical Climate Questionnaire, developed by Bart Victor, John B. Cullen, (1987, 1988), and James W. Bronson (1993), was used as the instrument in investigating the ethical perceptions of the accountants. Factor analysis results extracted seven dimensions and all of them were originally identified from the based theory of Ethical Work Climate of Cullen, Victor, \& Bronson (1993). These are Rules/Codes, Caring, Self-Interest, Social Responsibility, Efficiency, Instrumentalism, and Personal Morality. Results showed that Rules/Codes, Efficiency, and Instrumentalism dimensions have no significant difference between Filipinos and Taiwanese. The analysis indicated that caring, self-interest, social responsibility, and personal morality dimensions showed significant difference between Filipinos and Taiwanese accountants.
\end{abstract}

Keywords: Ethical Work Climate, ECQ, factor analysis, self-interest, social responsibility, personal morality, Filipino accountants, Taiwanese accountants.

\section{INTRODUCTION}

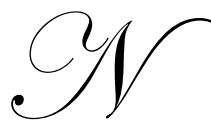

owadays, the Philippines and Taiwan are actively associated through several fields of businesses, from small-scale, medium-scale enterprises, and corporate level business. A multi-national company in Taiwan is currently operating its business in the Philippines, where it both employs Filipino and Taiwanese accountants in performing accounting and financial reporting for the company, as well as auditing. The accounting profession is said to be an important part for the Philippines and Taiwan in stating their stability and integrity as a company in terms of financial reporting. Although there are possibilities that serious reports of accounting issues have taken place in both countries, this research objective is to better understand whether Filipinos and Taiwanese accountants have the tendency to show any ethical or unethical behavior.

The scope of the study is concentrated within the dimensions of Ethical Work Climate (Cullen et al., 1993) among Filipino and Taiwanese accountants.

\section{Accounting In The Philippines And Taiwan}

"Many financial institutions, including banks, savings and loan associations are in the limelight, often amid scandals over bad or improper loans, embezzlements, poor management, and allegations of self-serving, unethical, and illegal acts performed by executives, managers and employees alike" (Datu-Evangelista, 1997, p.34). From these activities that have taken place in today's society, ethics has become more interrelated with moral responsibilities of accountants. Knowing the accounting cultures in the Philippines and Taiwan would give an overview on how this kind of profession is being practiced from their respective countries. 


\section{Accounting In The Philippines}

Accounting has been practiced since the early seventeenth century during the Spanish colonization in the Philippines. On the $17^{\text {th }}$ of March in 1923 the first accountancy law was passed by the Philippine legislature. From that time, accounting practices have gradually developed over the years. The Philippine Institute of Certified Public Accountants (PICPA) is an institute that is responsible for establishing and monitoring accounting standards in the Philippines. The code of professional ethics in the Philippines is similar to the framework of the American accounting system.

\section{Accounting In Taiwan}

After incurring some problems from Chase Manhattan Bank of the US and from other foreign banks in Taiwan regarding incompetent opinions of audit reports, the Accounting Research and Development Foundation of the R.O.C. was established in June of 1984 and became the organization that established the accounting principles in the country (ARDF, 2005). The foundation's intention is to improve the country's accounting and auditing performances. It should be based on specified standards of financial and accounting standards by an unbiased and independent institution able to promote educational accounting training. It is composed of the Financial Accounting Standards Committee (FASC), Auditing Standards Committee (ASC), Financial Accounting Issues Task Force (FAITF), Accounting Research Monthly Publication, and the Secretarial Unit in charge of routine business operations (ARDF, 2005). As with the Philippines, the accounting principles are similar with US accounting standards that aims at enhancing Taiwan's accounting level, propelling continuous development of accounting and auditing standards, helping to build a healthy accounting system for industrial and commercial enterprises, and nurturing accounting professionals (ARDF, 2005).

\section{Code Of Ethics In The Philippines}

The Code of Ethics in the Philippines is developed for professional accountants who are identified as Certified Public Accountants (CPA) and hold a license granted by the Board of Accountancy. This code is "based on the International Code of Ethics for Professional Accountants developed by IFAC" (PRC Board of Accountancy, 2004, p. 2) and implies that mandatory implementation and rendering professional services of accountants in the Philippines.

The Code of Ethics in the Philippines is comprised of three parts: "Part A - Applicable to All Professional Accountants, Part B - Applicable to Professional Accountants in Public Services, and Part C - Applicable to Employed Professional Accountants" (PRC, Board of Accountancy, 2004, p. 1). The Board of Accountancy (2004) stated that Part A covers the general laws applicable to "all professional accountants" (p. 17). It is composed of seven sections namely: Integrity and Objectivity, Resolution of Ethical Conflicts, Professional Competence, Confidentiality, Tax Practice, Cross Boarder Activities, and Publicity. Part B states law concerning accountants who are engaged in public practice and services, is comprised of seven sections namely: Independence for Assurance Engagements, Professional Competence and Responsibilities Regarding the Use of Non-Accountants, Fees and Commissions, Activities Incompatible with the Practice of Public Accountancy, Client's Monies, Relations with Other professional Accountants in Public Practice, and Advertising and Solicitation. Lastly, Part C covers law about employment of professional accountants and comprises five sections, namely: Conflict of Loyalties, Support for Professional Colleagues, Professional Competence, and Presentation of Information (PRC, Board of Accountancy, 2004).

The Code of Ethics in the Philippines is also prepared for professional accountants or CPAs, which serves as the guideline for the accounting practice.

\section{Code Of Ethics In Taiwan}

The code is presented by the CPA Association of Republic of China (ROCCPA, 2007). The Code of Ethics in Taiwan is comprised of four parts: Professional CPA/Firm with Clients, Technical Guidelines for CPA, Service 
Operation of CPA, and Service Performances of CPA (ROCCPA, 2007). The first part deals with the responsibilities and liabilities of CPAs among their clients. This part covers five sections, namely: Integrity and Objectivity, Due Care, Trust, Confidentiality of Information, and Secrecy of Business or Trade Information of the client. The second part covers the technical standards for accountants in performing services with clients or firms. This part covers two sections, namely: Competence and Credibility of an accountant in expressing their opinion about the reviewed and complied transactions with the client. The third part is about CPAs service operations. This part of code of ethics comprises five sections, namely: Advertising, misleading Information by stating untrue, exaggerated, and criticism about other business entity with clients, unsolicited (direct, indirect, or implied) returned favors for the client (Guanxi), Revenue Service Fees, and Commissions and Charges. Lastly, the code covers the laws concerning the accountant's technical standards in performing of services. This part comprises ten sections, namely: usage of CPA license and non acceptance of non-CPAs as a partner in business firms, Trade name license, Independence, Authenticity of documents, CPA's role in the operation of the business, CPAs limitation regarding other CPA's services, performance of services in accordance to the contract, Soliciting consents of a CPA to another concerning acquiring services of the CPA, CPA firm's treatment among hired employees, and CPA performance of services according to the rules and laws.

\section{Filipino Culture}

The Philippines has its own diversity of local cultures across the islands. Although this kind of diversity exists, the roots of Malay and influences of Chinese, Indian, Hispanic, and American cultures are widely inherited by the local people. Nowadays, Philippine culture is so diverse, its people have developed a flexibility to adapt easily to changes. Although this kind of culture exists, there are still several unique values possessed by Filipinos. Amor propio is a characteristic where Filipinos, especially men, demonstrate their individual pride and self-esteem. Another is the comprade system, which is widely practiced throughout the island and usually occurs with an affinity to another person through baptism, confirmation, or marriage (Church, 1987, Church 1988, Church \& Katigbank, 2000). The relationship is extended with the exchange of favors through job hunting, etc. Another set of highly valued traditions (Church \& Katigbank, 2000) or personality characteristics are pakikisama (to get along with), hiya (to feel shame), utang na loob (to be grateful), delicadeza (to be cautious), mapagbigay (to be generous), makiramay (to share), pagtitiis (to endure), and pagtitimpi (to suppress). These values are widely practiced and have both advantages and disadvantages. Usually these highly valued traditions are designed to be advantageous; to keep a good relationship among peers and the working environment. They sustain the sincerity and humility of people among their friends and co-workers. On the other hand, they reveal weaknesses that allow other people to take advantage of a situation. In terms of cardinal virtues (Church \& Katigbank, 2000) which describe a typical Panay worker, consist of pagtugsiling (compassion), the ability to repress oneself giving a benefit for others, kabalaka deals with the care for other's sake; kalulo (fondness of the heart) which relates to the sensitivity or affection towards other people; and lastly kakugi and kapisan which dwells on the trait of being industrious, diligent, and attentiveness to detail. These cardinal values define the complex personality of a Filipino worker who may or may not practice these virtues in order to be called a good and ideal worker.

\section{Taiwanese Culture}

Taiwan is composed of a native people, referred to as Aborigines, as well as Taiwanese, and Mainland Chinese. Europeans, particularly Portuguese and Dutch, as well as Japanese, have formerly colonized Taiwan. The Taiwanese culture is similar with Chinese culture in terms of religious practices. Taiwanese inherited the practice, values, and tradition of Confucianism mixed with Buddhist and Taoist beliefs (Huang, 2000; ESLIsland.com, 2003). Confucianism has an impact among Taiwanese with four consistent traits: (1) socialization within the family unit; (2) a tendency to help the group; (3) a sense of hierarchy and of its naturalness and rightness; and (4) a sense of complementarities in relationship (Huang, 2000).

Huang (2000) stated that Confucian teachings emphasize a peaceful environment that individuals as well as their relationship among other people and in the society should be consistent and lasting. From this statement, the famous culture of "Gao Guanxi" or colloquially known as "Guanxi" exists among Taiwanese relationships. Huang (2000) has defined "Gao Guanxi as (the exploitation of personal relations or human networks) an activity that the 
suppressed class often uses to show their association with power and to solve their practical, daily life problems" (p.3). This means that individuals can share and help one another without expecting anything in return if no one from each side takes the advantage over one's kindness and helpfulness. However, in reality, guanxi is widely embraced and has substantial implication among Taiwanese. Rengqing (favor) and mianzi (face) are among relationships connected with the practice of guanxi and often times blended with guanxi (Huang, 2000). The major principles of Confucianism include jen (humanism), yi (righteousness), li (the rites and manners), chih (wisdom or intelligence), and shin (trustworthiness) (Lau 1979). Most Taiwanese people tend to keep their social status as respectable as possible and losing 'face' is one of the important observed values. Shame or disgrace affects the whole family, as well as the general reputation in the society.

Generally, Taiwanese people are friendly and industrious, motivated by social harmony, with an emphasis on self-control, resilient, respect for authority and value age, family and friends. Taiwanese people have a sense of valuing relationships among family and friends which they consider the core of social values. They also work hard and value education; considered an important aspect in improving one's personality (Huang 2000).

Filipino and Taiwanese people possess some common attributes. Both of the nationalities possess colonial influences, such as Chinese culture. Guanxi of Taiwan is similar to the compadre system of Philippines, where maintaining good relationships is an advantage for special treatment; especially for asking favors on work and services. Paggalang at pagmamalasakit of Filipinos are similar with valuing family and friends for Taiwanese. Both citizens value hard work described by literature reviews and articles (Andres, 1989).

\section{Base Theory}

The Ethical Work Climate, developed by John B. Cullen, Bart Victor(1987, 1988), and James W. Bronson(1993) stated that organizations take into responsibility for any ethical or unethical actions that takes place among their employees and likewise can initiate and implement ethical work climate.

Ethical Climates are conceptualized as general and pervasive characteristics of organizations, affecting a broad range of decisions (Victor \& Cullen, 1988). The participants of the questionnaire view different kinds of behavior, whether decision-making or their compliance in the organization's practices and procedures (Cullen et al., 1993).

The Ethical Climate covers two dimensions of theoretical typology of ethical climates (Victor \& Cullen, 1988); one dimension is ethical criterion, which is used for the organization's decision-making, and locus of analysis, the second dimension, refers to ethical decision-making.

The ethical criterion dimension is the dimension that covers three major classes of ethical theory (Victor \& Cullen, 1988) and these are egoism, benevolence, and principle. Egoism is defined as the maximization of selfinterest (VanSandt, 2001). This means that a person believes in themselves, irrespective of opposed situations from society or opinions of other people to preserve its dignity as an individual. The second class is benevolence, where "people tend to be less cognizant of laws and rules and may also be amenable to arguments employing rules or principles" (Victor \& Cullen, 1988, p.105). This explains that an argument or discussion with a person who has lesser knowledge or ignorance of the law or rules might be ineffectual. Principle is the last class of ethical criterion dimension where "people who are principled tend to be less sensitive to particular effects on others" (Victor \& Cullen, 1988, p. 105). This kind of situation usually happens when a worker who is honest and loyal becomes the enemy of another when breaking office policies in the work place. The honest and loyal employee takes some action by reporting the other employee to the management without any second thoughts as long as they know that there is a violation of the policy.

Another part of the Ethical Work Climate is the locus of analysis dimension. This dimension represents the different sources of influences and motivation where a person might conceive its own perceptions on ethical or unethical issues. Victor \& Cullen (1988) stated that it is a referent group identifying the source of moral reasoning used for applying ethical criteria to organizational decisions or the limits on what is considered the ethical analyses 
of organizational decisions. Individual, local, and cosmopolitan are the categories that comprises the second dimension. This locus of analysis demonstrates that ethical climate is an organizational concept (Victor \& Cullen, 1988).

Locus of individual "is external to the focal organization in the sense that the prevailing normative climate supports a referent for ethical reasoning located within the individual" (Victor \& Cullen, 1988, p.106). This locus explains that perceiving a kind of work climate within an organization can depend on how an individual perceives its environment from their own point of view. While individual locus focuses on oneself, the local locus "specifies sources of ethical reasoning within the organization, such as the workgroup" (Victor \& Cullen, 1988, p. 106). Victor $\&$ Cullen (1988) also mentioned that for the local role, "the important reference group or sources of role definitions and expectations are contained within the social system" (p.106). This explains that within organizations, employees might perceive a positive or negative value depending on the type of group a person belongs. A group, which places a high value on morale, tends to influence an individual to perceive this kind of thinking; likewise the same with workgroups that place a low value on morale.

A level, which specifies organizational sources of ethical reasoning external to the focal organization, such as professional associations or a body of law (Victor \& Cullen, 1988), is what is called cosmopolitan. Developed law-based environments use this locus to perceive norms or morale, which are acquired from other sources outside the organization.

Combining the two dimensions, ethical criterion and locus analysis, forms nine different criterions in order to describe the moral reasoning of an employee or individual.

The locus of the individual when combined with ethical criterions results in the following dimensions: egoism-individual (EI) results in self-interest, benevolence-individual (BI) resulting in friendship, and principleindividual (PI) results in personal morality. For local locus, combined with the ethical criterions three dimensions are created. They are as follows: egoism-local (EL) resulting in company profits, benevolence-local (BL) results in team interest, and principle-local (PL) explains the dimension of company rules and procedures. For the last three sets of dimensions, the analytical combination of ethical criterion and locus of analysis, describe the following: egoism-cosmopolitan (EC) forms the dimension, of efficiency while benevolence-cosmopolitan (BC) and principlecosmopolitan (PC) form the dimensions of social responsibility and laws and professional codes respectively.

The dimensions resulting from ethical criterion and locus analysis will help the researcher identify and understand the ethical climate values that Filipino and Taiwanese accountants possess.

\section{LITERATURE REVIEW}

Ethics is a sensitive issue surrounding the practice of accounting that has taken on a more serious role the last few years. Nowadays, accountants face a test of their character by either following their normative and ethical point of view or simply 'take the easy option' (Lewis, 2006). The Code of Ethics in the accounting professions has evolved from eight core attributes (Integrity, Objectivity, Professional Competence, Due Care and Timeliness, Technical Standards, Professional Behavior, Confidentiality, and Independence, (Datu-Evangelista, 1997) to five principles; Integrity, Objectivity, Professional Competence and Due Care, Confidentiality, and Professional Behaviour. These changes are encouraged as a standard measure for accounting practitioners around the world to protect them from different kinds of threats, as well as provide them with knowledge to handle uncomfortable and critical situations (Lewis, 2006).

The Ethical work climate (EWC) shares an interest with individuals and researchers from many different fields. Several authors had raised their own ethical work climate issues. Wittmer and Coursey (1996, p560) stated, "Ethical climate is an extension of two related concepts - work climates and organizational culture......shared perceptions of the ethical aspects of an organization's culture". The two authors explained that these climates may mirror the culture of the organization but most likely will reflect the moral surface of the organization. A similar view from Vardi (2000) stated that ethical climates are embedded in the organizational climate which is embedded 
in organizational culture. This explains the possible reflection of ethical climates on local restrains and direction for behavioral actions of individuals.

Parboteeah et al. (2005) suggested that ethical culture differences would reflect a greater difference in perceiving ethical climate values. These studies showed different approaches for studying the ethical climate in different industries and sectors of society.

Wittmer and Coursey's (1996) research took place with public and private companies. The results indicated that public organizations tend to possess more awareness of moral responsibility and public commitment but perceived lesser ethical climates than private organizations.

Parbooteeah's et al., (2005) research study focused on individuals from U.S. and Japanese accounting firms, where these individuals are employed by the Big Five accounting firms from each respective country. The findings of this research suggested that ethical culture had an impact among Japanese that fosters their knowledge in situational decision-making instead of principles. Compared with Japanese accountants, Americans scored high with the principle aspect because they are more associated with different groups or affiliations. On the lighter side, egoistic climate existed for both Americans and Japanese due to the standardization of accounting principles and the affect US-Western accounting principles on Japanese systems. Parboteeah's et al. (2005) research tried to associate the EWC with national culture, by comparing American and Japanese accountants. The results revealed that it is not the national culture that influences the perception, but rather the ethical culture or the cultural background that influences the accountants' perceived ethical work climate.

In contrast, Wittmer and Coursey (1996) and Vardi (2001) suggested that organizational culture has a greater impact on individuals in perceiving ethical climate within their organization or institution.

Cohen (1995) associates ethical climate with socioeconomic perspective. The study proposes a moral climate continuum to establish ethical climate among business firms. It covers organizational process and inclusive social integration. Political, technical, and cultural process constitutes organizational process while positive moral climate (goal emphasis, means emphasis, reward orientation, task support, and socioemotional support) represents inclusive social integration. Cohen believes that adopting this kind of perspective in different management fields may promote an ethical environment in an organization; thus develop a more reliable but positive moral workplace.

\section{RESEARCH METHODOLOGY}

This study aims to discover the ethical work climate(s) perceived by Filipino and Taiwanese accountants. EWC dimensions will serve as the independent variables for this research study. The independent variables will determine whether the possible factors can show any significant effect on dependent variables, which are the Filipino and Taiwanese accountants.

\section{Research Hypotheses}

Arnaud and Schminke (2006) stated that ethical work climate is the shared perceptions regarding prevalent ethics-related values, norms, attitudes, and behaviors among members of a social system, their view parallels Victor and Cullen's (1988) definition that ethical work climate reflects employees' collective perceptions of ethical events, ethical practices, and procedures. The ethical climate covers two-dimensional areas which are the locus of analysis (covers the individual, local, and cosmopolitan) that deals with the perceived values from different source of influence and motivation while ethical criterion (principle, benevolence, and egoism) deals with the perceived values from a group or organization. From there, ethical climate produces nine ethical climate dimensions such as self-interest, friendship, personal morality, company profit, team interest, company rules and procedures, efficiency, social responsibility, and the laws and professional codes that represent the values that individuals might conceive within their organization. Using these theoretical aspects of ethical climate, this research study will focus on understanding the ethical work climate values that Filipino and Taiwanese accountants perceive from their organization or institution. 
After acknowledging the factors that identify the ethical values, we will determine if there is a significant difference between Filipino and Taiwanese accountants on the perceived ethical work climate value(s) from their organization or institution.

From this research question, we can formulate the hypothesis:

$\mathbf{H}_{1}$ : $\quad$ Filipino and Taiwanese accountants have no significant difference on the perceived ethical work climate value(s) from their organization or institution.

This hypothesis expresses its objective to discover and understand whether Filipino and Taiwanese accountants may or may not show any significant difference in perceiving any ethical work climate within their organization or institution. It is important to know the possible values that they perceive in order to understand the attitudes towards performing their job as accountants in their respective organizations. From the literature review on cultural backgrounds, both Filipinos and Taiwanese display camaraderie and fondness of good relationship with other people along with their preservation of social status. These values might contribute or directly affect the possible result of the hypothesis. It may or may not help to understand the work climate attitude of these accountants, such that it can reflect or affect in the overall performance results of the company as well.

\section{Research Instrument}

The research instrument used for this research study was the Ethical Climate Questionnaire (ECQ) developed by John Cullen, Bart Victor (1987, 1988), and James W. Bronson (1993). The questionnaire is composed of a 36-item likert scale representing the nine dimensional values of ethical work climate. The thirty-six items of ECQ are answerable in interval scale ranging from the scales of 1 (completely false) to 5 (completely true). Personal information was also asked from the respondents. Two sets of questionnaire were prepared. An English version was distributed to the Filipino accountants and Mandarin Chinese for Taiwanese accountants.

The Chinese version of the ECQ was translated by the author and translated back to English by a professor from the Applied English department at Southern Taiwan University in Taiwan. A native American professor validated the translation.

Research samples are basically composed of Filipino and Taiwanese accountants who are performing accounting related jobs in the Philippines and Taiwan. The participants are either CPA or non-licensed accountants to the extent they hold an Accountancy degree and are accountants by profession. Accountants from family owned businesses were not included in the sample, since they would reflect a biased perception on the work climate in the company.

\section{Data Collection}

A total of 514 questionnaires were distributed, 265 from Philippines and 250 from Taiwan. From this, Philippine sample size had an $83.40 \%$ response rate from 201 useful sets of questionnaires out of 265 sets distributed, where 46 sets were unusable and 18 sets unreturned. For the Taiwan sample, 163 sets of questionnaires were usable out of 250 sets distributed, giving a $65.20 \%$ response rate. Forty sets are unusable while the remaining 47 sets were not returned.

The low response rate of $65.20 \%$ from the Taiwan sample reflects the "mianzi" or the "face" value of Taiwanese culture. While conducting the survey, most of the Taiwanese accountants were very hesitant to participate in the survey. The sensitive topic of the research about ethics led the researcher to receive lower responses from certain individuals. Most of them responded that results might imply a negative impact on the reputation of the company even though anonymity of the respondents was highly valued and respected by the researcher. 


\section{Research Methods}

Factor analysis was used for this research. This extracted the data into factors that determined the dimensions of EWC among Filipino and Taiwanese accountants. The results will answer the research question.

\section{Reliability Measure Of The Instrument}

Measuring the reliability of the instrument is one important step to show the internal consistency of the constructs. It can also help to determine the ability to measure the homogeneity or independence of the constructs.

Table 1: Reliability Measure of ECQ

\section{Relia bility Sta tistics}

\begin{tabular}{|c|c|c|}
\hline $\begin{array}{l}\text { Cronbach's } \\
\text { Alpha }\end{array}$ & $\begin{array}{l}\text { Cronbach's } \\
\text { Alpha Based } \\
\text { on } \\
\text { Standardized } \\
\text { Items }\end{array}$ & $\mathrm{N}$ of Items \\
\hline .894 & .898 & 36 \\
\hline
\end{tabular}

The reliability statistics result showed that the ECQ has a reliability measure of 0.894 , which is above the standard reliability measure of 0.70 . Each item or construct in the instrument also showed reliable measures ranging from 0.786 up with a standard deviation of 1.130 .

\section{Factor Analysis}

Factor Analysis was used to determine the possible ECQ dimensions possessed or perceived by the accountants. This research applied 0.5 for this study. This was based on the rule of thumb suggested for checking construct validity. The SAS program was used to analyze the data. Principal component factoring (PCF), principal axis factoring $(\mathrm{PAF})$, and varimax rotation were the methods used in extracting the factors in the data analysis.

Several procedures were done in performing factor analysis. Initially, there were eight factor loadings formed from the first procedure with a $60.620 \%$ of total variance explained. Kaiser-Meyer-Olkin (KMO) measure is 0.888 , which shows that the homogeneity of the constructs are adequate to continue running the factor analysis. The following sequence of procedures took place using Principal Component Factoring (PCF), Principal Axis Factoring (PAF), and Varimax Rotation in extracting the number of components to be used in this research study.

First, Kaiser's Measure of Sampling Adequacy (MSA) was performed to check whether there were values lower than 0.5. There were no constructs contained below 0.5 and MSA checking was satisfied. Second, construct validity took place using the Principal Component Factoring (PCF) and Varimax Rotation. Constructs Q13, Q8, Q22, Q19, Q2, Q11, Q36, and Q27 contained factor loadings lower than 0.5 and were removed one by one after each rotation. Results of the final rotation are presented in table 2 with seven components extracted. Principal Axis Factoring (PAF) was the third sequence performed after reversing the negative score of Q9. Final results showed that $63.04 \%$ of the total variance could be explained by the seven factors extracted. A Square Root of the Standardized Residual Average (RMSR) equal to 0.025 displayed a good factor structure, smaller than the 0.05 .

The Second assessment is the reliability test. Reliability assessment involved Cronbach Alpha Reliability Coefficient and Correlation with Total. Table 2 shows the Cronbach Alpha Reliability Coefficient values for each factor. Cronbach Alpha Reliability test is satisfied where factors have Cronbach alpha ranges of 0.35 (acceptable value) up to 0.860 indicating high reliability. 
Table 2: Cronbach Alpha Reliability Coefficient Assessment on ECQ Factors

\begin{tabular}{|l|c|c|}
\hline \multicolumn{1}{|c|}{ ECQ Factors } & Cronbach Alpha & $\begin{array}{c}\text { Cronbach Alpha } \\
\text { on Standardized Items }\end{array}$ \\
\hline Rules/Codes & & 0.860 \\
\hline Caring & 0.860 & 0.828 \\
\hline Self-Interest & 0.829 & 0.729 \\
\hline Social Responsibility & 0.732 & 0.751 \\
\hline Efficiency & 0.754 & 0.677 \\
\hline Instrumentalism & 0.675 & 0.538 \\
\hline Personal Morality & 0.532 & -0.353 \\
\hline
\end{tabular}

Table 3 presents the summary of Reliability Results for each factors' constructs with their corresponding Cronbach Alpha values.

Table 3: Reliability Results per Constructs for ECQ Factors

\begin{tabular}{|c|c|c|c|c|c|c|c|}
\hline & \multicolumn{7}{|c|}{ E C Q CONSTRUCTS } \\
\hline & Q14 & Q15 & Q20 & Q24 & Q7 & Q26 & Q23 \\
\hline \multirow[t]{2}{*}{ Rules/Codes } & 0.825 & 0.840 & 0.833 & 0.838 & 0.854 & 0.847 & 0.846 \\
\hline & Q32 & Q35 & Q21 & Q31 & Q12 & Q5 & \\
\hline \multirow[t]{2}{*}{ Caring } & 0.783 & 0.792 & 0.784 & 0.814 & 0.794 & 0.834 & \\
\hline & Q10 & Q1 & Q33 & Q3 & & & \\
\hline \multirow[t]{2}{*}{ Self-Interest } & 0.634 & 0.616 & 0.649 & 0.761 & & & \\
\hline & Q30 & Q28 & Q34 & Q17 & & & \\
\hline \multirow[t]{2}{*}{ Social Responsibility } & 0.603 & 0.636 & 0.681 & 0.818 & & & \\
\hline & Q4 & Q29 & Q25 & & & & \\
\hline \multirow[t]{2}{*}{ Efficiency } & 0.619 & 0.554 & 0.575 & & & & \\
\hline & Q18 & Q16 & & & & & \\
\hline \multirow[t]{2}{*}{ Instrumentalism } & - & - & & & & & \\
\hline & Q6 & Q9 & & & & & \\
\hline Personal Morality & - & - & & & & & \\
\hline
\end{tabular}

Factor 1 (Rules/Code) contains the dimensions of Principle-Cosmopolitan (PC), Principle-Local (PL) and Benevolence-Cosmopolitan (BC). Responses of participants loaded on the same factor that explains rules and regulations and laws and professional codes are treated in the same level, and serves as the first important ethical climate dimension in their organization.

Factor 2 (Caring) is the combination of Benevolence-Individual (BI), Benevolence-Local (BL), and EgoismIndividual (EI) dimensions of ECQ. Each construct loaded in this factor describes that accountants perceived the ethical climate of caring as being more concerned in establishing and maintaining good relationship among coworkers.

Factor 3 (Self-Interest) is composed of constructs of Egoism-Individual (EI) and Principle-Individual (PI) dimensions. Factor loadings show that personal interest exists in the organization. Results indicate that people in the organization tend to perform their task in their own way to fulfill personal satisfaction. 
Factor 4 (Social Responsibility) contains Benevolence-Cosmopolitan (BC) and Egoism-Local (EL) dimensions of the ethical work climate. The result of the factor loadings explains that individuals perform their tasks with their level best for the organization while taking precautions for social awareness or responsibility.

Factor 5 (Efficiency) is the combination of Egoism-Local (EL) and Egoism-Cosmopolitan (EC) dimensions. Company profit and efficiency comprise the factor loadings. Individuals see their organization mostly concerned in attaining greater profit while efficiency is being observed by each employee.

Factor 6 (Instrumentalism) is the combination of Principle-Local (PL) and Benevolence-Individual (BI). This factor is described differently and the label is not among the nine dimensions of ECQ. Each construct contains different purposes that lead to assumption that each construct acts as a "means" or an "aid" in providing solutions for a certain circumstance to occur in the organization.

Factor 7 (Personality Morality) is formed by the constructs of Principle-Individual (PI). Factor loadings explain that most of the individuals are morally responsible for their actions distinguishing "right from wrong" and/or to be "ethical or unethical".

Results from the factor analysis helped the researchers to identify the perceived ethical work climate values of the accountants. Factors such as Rules/Codes, Caring, Self-Interest, Social Responsibility, Efficiency, Instrumental, and Personal Morality are the dimensions emergent in this research study. Extraction method and rotation method using Principal Component Analysis and Varimax with Kaiser Normalization were performed respectively. Results showed that $63.04 \%$ of the total variance is explained by the six factors identified from the analysis. Independent Sample T-test is the methods used by the researchers to identify the significant or insignificant difference and influences of the demographic variables among the Ethical Work Climate factors.

Table 4: Independent Sample T-test on ECQ Dimensions on Nationality

\begin{tabular}{|l|c|c|c|}
\hline \multirow{2}{*}{ ECQ DIMENSIONS } & \multicolumn{2}{|c|}{ M E A N S C O R E S } & \multirow{2}{*}{ SIGNIFICANCE } \\
\cline { 2 - 3 } & Filipino & Taiwanese & 0.1927 \\
\hline Rules/Codes & 3.8962 & 3.9851 & 0.0116 \\
\hline Caring & 3.3425 & 3.1656 & $<0.0001$ \\
\hline Self-Interest & 2.6517 & 3.6150 & $<0.0001$ \\
\hline Social Responsibility & 3.7313 & 3.1656 & 0.2268 \\
\hline Efficiency & 4.1509 & 4.0573 & 0.3081 \\
\hline Instrumentalism & 3.1169 & 3.2025 & $<0.0001$ \\
\hline Personal Morality & 2.5323 & 2.9479 & \\
\hline
\end{tabular}

\section{CONCULSION AND DISCUSSIONS}

Factor analysis results extracted seven dimensions and all of them were originally identified from the base theory of the Ethical Work Climate of Cullen, Victor, \& Bronson (1993). These are Rules/Codes, Caring, SelfInterest, Social Responsibility, Efficiency, Instrumentalism, and Personal Morality. The sixth factor was labeled as Instrumentalism, which is often used by researchers in describing a factor. Factor seven is labeled as "Personality morality" because each construct contains a different purpose, to be an "aid" or "means" in identifying certain circumstances occurring in the organization. It also helps or gives benefits to others satisfying their personal goals or intentions. These results helped to identify the ethical work climate.

\section{Nationality: Filipino vs. Taiwanese}

Results showed that Rules/Codes, Efficiency, and Instrumentalism dimensions have no significant difference between Filipinos and Taiwanese accountants. The first dimension explains how organizations are concerned and aware of certain rules of the company as well as following the rules of professional conduct set for 
accounting practitioners. The results from the tests revealed that these two nationalities have no significant difference in perceiving the said ethical climate. Philippine and Taiwanese accounting systems originated from the American accounting system. Both financial accounting standards and standard settings were based on IASB, FASB, and SFAS (PIA, 1957 \& ARDF, 2005). Efficiency also shows no significant difference. Accountants have the knowledge of working efficiently and professionally in accordance with Code of Conducts, as well as in accordance with Accounting Standards and the company rules and guidelines. For the dimension Instrumentalism, results showed that both Filipino and Taiwanese accountants demonstrated or applied certain "aids" and "means" as long as good relationships and reputation was maintained without harming the company's interest.

Caring, self-interest, social responsibility, and personal morality dimensions showed significant difference between Filipinos and Taiwanese. The Cultural background of each country is assumed to be the reason for this significant difference. Filipinos possess a set of highly valued traditions such as, pakikisama (to get along with), mapagbigay (to be generous), and makiramay (to share) (Church, 1989; Church \& Katigbank, 2000). In addition, paggalang at pagmamalasakit (respect and concern), pagtulong at pagdamay (helping), and pakikipagkapwa (human concern and interaction as one with others) are among the values that were already embossed and established within Philippine culture. For Taiwanese culture, Confucianism is described as an influence to their culture. Huang (2000) stated that Confucianism directly influences Taiwanese with traits of helping other people and establishing a complementing relationship among peers. These values possessed by Filipinos and Taiwanese correlate with the dimension of Caring, moreover relates to concern about other people's welfare. Although the mean scores are quite close, the approach for Caring is different between the two nationalities.

Different traits from each culture explain the significant difference on the dimension of Self-Interest. There can be two possible explanations from the Filipino side: favorable and unfavorable traits. The traits of leveling (crab mentality), and walang bigayan-lamangan mentality (selfish but taking advantage over the other's worth for success) are among the unfavorable traits of Filipino culture. For favorable ones, non-interference (minding your own business) is a common trait to avoid embarrassing or shameful situation for both parties. Gao guanxi relationship can explain the significant difference about the second dimension. Gao guanxi can be also taken in a recommendable and less recommendable. Guanxi becomes recommendable when someone tries to help family members, friends, and/or other peers in a most possible way. Guanxi becomes less recommendable when people try to take advantage over a person for his own benefit, even if it will hurts another person, similar to walang bigayanlamangan trait. In short, the approach of Self-Interest is different between the two nationalities.

The cultural backgrounds of the subjects can explain the results from Social Responsibility, Personal Morality, and Efficiency dimension. These three dimensions are explained in Philippine context. Hiya (shame) along with mabuting kaugnayan (attachment, affiliation) - dealing with Social Responsibility, delicadeza (to be cautious) and pagpuno sa kakulangan (understanding limitations) - explaining the concept of Personal Morality, and Efficiency is explained by traits of pagkamatiyaga (perseverance, diligence), kaalaman at kahusayan (knowledge and competence). Jen (humanism), i (faithfulness), and chi (wisdom) explains the significant difference in the context of Taiwanese culture (Huang, 2000). Other qualities such as friendly, industrious, and self-control are also traits that explain Taiwanese culture's influence on the three dimensions. The level or degree of expression and practice of the said dimensions resulted in the possible significant difference among Filipino and Taiwanese accountants.

Compared to the study of Parboteeah et al., (2005), this research took cultural background as a basis to explain the significant or lack of significant difference among the nationalities.

\section{Implications Of The Research Study}

The researcher intended to elaborate each ethical work climate dimensions to show its differences and similarities between Filipino and Taiwanese, as well as the possible influence of gender, civil status, age, company/institution, and years of job experience of the accountants. Research studies about ethical climate, particularly on Filipino and Taiwanese accountants, are not yet established. This paper may serve as a starting point and a guide to explore and improve the analysis and results of ethical work climate study among Filipino and 
Taiwanese accountants. This study also covered different levels of accountants, reflecting the possible biased perception coming from certain group or level of employees (non-managerial versus managerial function). The research study also wants to accentuate that cultural background may convey a basis of the similarities and differences of the subjects.

\section{Limitations Of The Study}

The research study is limited within the metropolitan areas and main cities of Philippines and Taiwan. Makati City, Manila, Mandaluyong City, and Quezon City are the areas where Philippine respondents were measured. Taipei City and Tainan are the only areas that comprise the Taiwan sample. This is due to the researcher's accessibility and capacity to conduct a wider scope of research. The results may not represent the perception of the whole population of accountants in the Philippines and Taiwan. This may also improve the linear relationship results between ethical dimensions and demographic variables. Another is the unclassified type of accountants participated in the research. There were no distinction between CPA and non-CPA, and accountants were taken as the same type in this study.

\section{Recommendation}

Although the scope of the research area consisted of accountants from the head office of the respective companies, the researcher recommends other interested individuals have a wider and larger field of population.

The objective is to attain a more comprehensive number that can represent the perceived climates of Filipinos and Taiwanese accountants. Analyzing the impact of ethical climate dimensions among CPA and nonlicensed accountants is also recommended. It may improve and show a better result among the dimensions, particularly with the efficiency dimensions in government and private company/institution.

\section{AUTHOR INFORMATION}

Chiulien Chuang Venezia, DBA, CPA, has been teaching Accounting since 1992. She is an assistant professor of Accounting at Frostburg State University, Maryland. Her Research Interests include Cross-cultural ethics, Earnings management, and Financial performance. She has published papers in the International Business \& Economics Research Journal, the Journal of American Academy of Business, Cambridge, and Journal of Nan-Tai College. Currently, her research focuses on Ethical Work Climates in the public and private sectors.

Catherine Gallano is presently working as a Treasury Assistant at Uni-President (Philippines) Corporation. She was born in 1978 in Manila, the Philippines and is the eldest among two children of Nicanor and Elizabeth. Her brother, Daryiel is a newly graduate from Airlink International Aviation School. She received her bachelor's degree in Accountancy at Far Eastern University in Manila, and a Master's in Business Administration at Southern Taiwan University in Taiwan. She has been working for almost ten years in distribution and manufacturing companies in the Philippines. Dr. Chiulien Chuang Venezia was her professor and thesis adviser during her MBA study at Southern Taiwan University in Taiwan.

\section{REFERENCES}

1. Accounting Research and Development Foundation in Taiwan (ARDF) (2005). [Web document]. Available: http://www.ardf.org.tw/english/. [2007, 11 April].

2. $\quad$ Andres, T.D. (1989). Positive Filipino Value. New Day Publishers.

3. Arnaud, A.U., \& Schminke, M. (2006). Beyond the organizational bases of ethical work climates: a new theory and measure. [Web document]. Available: http://www.business.uiuc.edu/aguilera/Papers/schminke\%202006.doc. [2006, 31 August].

4. Certified Public Accountant Association, R.O.C (ROCCPA) (2002). Code of Ethics for Professional Accountants. [Web document]. Available: http://www.roccpa.org.tw/Download.php. [2007, 15 June]. 
5. Church, T., Katigbak, M., del Prado, A., Valdez-Medina, J.L., Miramontes, L., \& Ortiz (2006). A crosscultural study of trait self-enhancement, explanatory variables, and adjustment. Journal of Research in Personality, 40, 1169-1201.

6. Church, T.A.; \& Katigbank, M.S. (2000). Trait Psychology in the Philippines. The American Behavioral Scientist, 44, 1, 73-94.

7. Church, T.A. (1989). Filipino Personality: A Review of Research and Writings. Manila, DLSU Press 1988.

8. Church, T.A. (1987). Personality Research in a Non-Western Culture: The Philippines. Psychological Bulletin, 102, 2, 272-292.

9. Cohen, D.V. (1995). Moral climate in business firms: A framework for empirical research. Academy of Management Journal, 1995, 386-390.

10. Cullen, J.B., Victor, B., \& Bronson, J.W. (1993). The ethical climate questionnaire: an assessment of its development and validity. Psychological Reports, 73, 667-674.

11. Datu-Evangelista, R. (1997). Ethics: the soul of a globalized practice of accountancy. Accountants' Journal, 50 (3\&4), 30-38.

12. ESLIsland.com (2003). History of Taiwan. [Web document].Available: http://www.eslisland.com/intro/History.html. [2007, 11 April].

13. ESLIsland.com (2003). Taiwan Culture. [Web document]. Available: http://www.eslisland.com/intro/Culture.html. [2007, 11 April].

14. Huang, Y. (2000). The personal influence model and gao guanxi in taiwan chinese public relations. Public Relations Review, 1-8.

15. Lau, D.C.(tanslated) (1979). Confucisus The Analects. England UK: Penguin Book.

16. Lewis, T. (2006). Comment inside the moral maze. Public Finance; Accounting Tax \& Periodicals, Jun30-Jul 6, 2006, 17.

17. Parboteeah, K.P., Cullen, J.B., Victor, B., \& Sakano, T. (2005). National culture and ethical climates: a comparison of U.S. and Japanese accounting firms. Management International Review, 45 (4), 459-481.

18. Philippine Institute of Accountants (PIA) (1957). The First Far East Conference of Accountants 1957 (28th, 29th, \& 30th of November and 1st December 1957) Senate Hall Congress Bldg., Manila. National Printing, Co., Inc., Manila Philippines.

19. Philippine Regulation Commission (PRC) (2004). Board of Accountancy - Board Law. [Web document]. Available: http://www.prc.gov.ph/portal.asp?pid=34. [2007, 16 June]

20. Ponemon, L.A. (1990). Ethical judgments in accounting: a cognitive-developmental perspective. Critical Perspective on Accounting, 1, 191-215.

21. SPSS, Inc. (1999). SPSS Base 10.0 Application Guide. Chicago, Illinois, USA: SPSS, Inc.

22. VanSandt, C.V. (2001). An examination of the relationship between ethical work climate and moral awareness. Unpublished doctoral dissertation, Virginia Polytechnic Institute and State University, USA.

23. Vardi, Y. (2001). The effects of organizational and ethical climates on misconduct of work. Journal of Business Ethics, 29 (4), 325-337.

24. Victor, C. \& Cullen, J.B. (1988). The organizational bases of ethical work climates. Administrative Science Quarterly, 33 (1), 101-125.

25. Victor, C. \& Cullen, J.B. (1987). A Theroy and Measure of Ethical Climate in Organizations. Research in Social Performance \& Policy, 9 , 1987, 51-72.

26. Wittmer, D., \& Coursey, D. (1996). Ethical work climates: comparing top managers in public and private organizations. Journal of Public Administration Research and Theory, 6 (4), 559-572.

27. Woodbine, G.F. (2006). Ethical climate types and job satisfaction: study of Chinese financial institutions. International Review of Business Research Papers, 2 (1), 86-99. 
28. Wu, M., Taylor, M., \& Chen, M. (2001). Exploring societal and cultural influences in Taiwanese public relations. Public Relations Review, 27, 317-336.

\section{NOTES}

